\title{
Optimization and characterization of sugar-cane bagasse liquefaction process
}

\author{
Mona Nasar, Aisha Emam*, Maha Sultan and A. A. Abdel Hakim \\ Dept. of Packing and Packaging Material Science, National Research Centre, 33 El-Tahrir St. Dokki, Giza, Egypt. \\ 'Faculty of Science, Chemistry Department, Suez Canal University, Asmallia, Egypt. \\ Monanassar65@yahoo.com, Aisha.Emam@hotmail.com, mahasultan21@yahoo.com, aaabdelhakim@yahoo.com
}

Abstract
Sugar-cane bagasse was liquefied in ethylene glycol/phthalic anhydride mixture catalyzed by sulphuric acid at temperatures $160-220^{\circ} \mathrm{C}$, liquefaction times $60-240$ minutes, and ethylene glycol amounts $5-20 \mathrm{ml}$ for each three grams of sugar-cane bagasse. The residue obtained was characterized by FT-IR, X-ray diffraction, and scanning electron microscope. The percentages of residue, average molecular weight, hydroxyl and acid numbers were determined as an estimate of polyol value of the liquid products. Optimal conditions for liquefaction were established: reaction temperature $160^{\circ} \mathrm{C}$, reaction time 180 minutes, and ethylene glycol amount $20 \mathrm{ml} /$ three grams sugar-cane bagasse.

Keywords: Liquefaction, polyol, molecular weight, hydroxyl number, acid number.

\section{Introduction}

Biomass, including wood and other agro-based waste materials composed of complex mixture of natural polymeric materials such as cellulose, hemicelluloses, polysaccharides, and lignin. A natural polyphenolic material represents the largest parts compared to resins and other components such as minerals which are present in smaller amounts and differ substantially between species. A major limitation to the use of wood and other agro-based wastes as a chemical feedstock is the structural and chemical variety of their components and difficulties with their solubility in various solvents. Solubility is an important parameter especially in the case of cellulose, which forms highly ordered fibrils in which the polar macromolecules attach strongly through hydrogen bonds. These tightly packed structures prevent the intrusion of solvents and reagents thus making cellulose a particularly difficult material to transform chemically. One approach to use agro-based wastes components is to chemically derivatives the agro-based components and thus increases their solubility in selected solvents (Andrej et al., 2005). Aliphatic alcohols (from $\mathrm{C}_{1}$ to $\mathrm{C}_{7}$ ) or polyols have been known for a long time to selectively dissolve the basic components of agriculture wastes (Rezzoug et al., 2002). Yao et al., (1999) investigated various polyols or their combination with other polar solvents as reagent in biomass liquefaction, such as polyethylene glycol (PEG), polycarbonate (PC 303), PEG/glycerin; PEG/1,1,1-Tris (hydroxymethyl) propane (TMP), and £-carpolactone $(\mathrm{CPL}) /$ glycerin. The obtained results showed that the liquefaction reaction using PEG/glycerin achieved the lowest residue content among all other used solvents. Krzan et al. (2005) studied the effect of different combinations of polyols with organic acids or mineral acids and reported that a combination of propylene glycol (PG) as the reagent solvent and maleic anhydride as the acid catalyst showed the best liquefaction results. The effect of ozone pre-treatment on wood, liquefaction time, temperature, and wood species on wood liquefaction with polyhydric alcohols has also been investigated (Kobayashi et al., 2005). Various products have been made from liquefied biomass with polyhydric alcohols (Kurimoto et al., 1999; Rezzoug et al., 2003). Epoxy resins were synthesized from PEG/glycerol liquefied wood as epoxy compounds such as diglycidyl ether of biphenyl and diglycidyl ether of ethylene glycol oligomers (Kobayashi et al., 2000). Starch, wood/starch mixture, corn bran, bark/starch mixture have been liquefied and used to prepare polyurethane foams (Yao, 1995; Lee, et al., 2000).

Efforts have also been made to recover the polyols from bio-based foams after their glycolysis degradation (Lee et al., 2005). Polyurethane films, resins, and adhesives have been synthesized from PEG/glycerol liquefied wood (Kurnmoto et al., 2001; Wei et al., 2004; Tohmura et al., 2005). Condensation reactions of degraded lignocelluloses components have also been investigated (Yamada et al., 2001; Kobayashi 2004). Therefore, the goal is to determine the optimum conditions of liquefaction process of lignocellulosic waste and evaluation of liquefaction products to be utilized in rigid polyurethane foam preparation.

\section{Materials and methods}

The biomass used was sugar-cane bagasse, which was donated by Qena of Pulp and Paper Company. Ethylene glycol and phthalic anhydride were technical grades, were obtained from UHDPE.Scharlau Chemie SA and Arabian Medical Scientific Lab. Sup. Company. Whereas all other

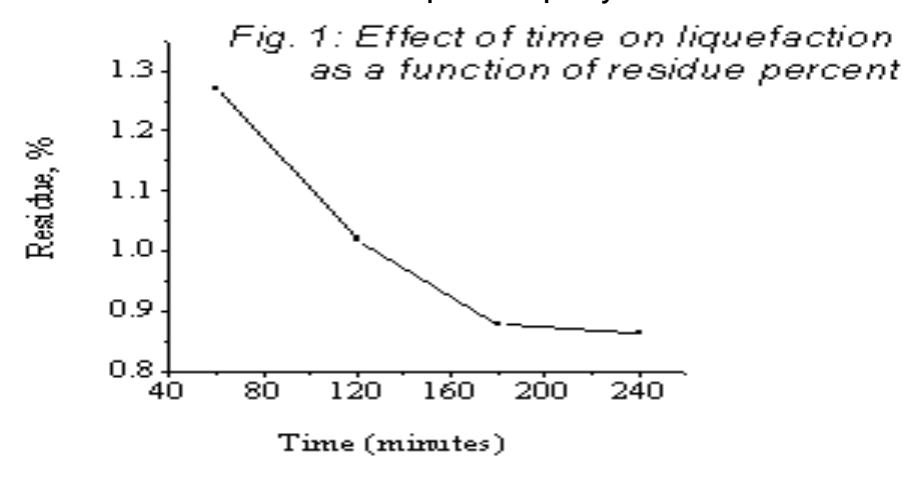

Research article

CIndian Society for Education and Environment (iSee)
"Sugarcane bagasse liquefaction" http://www.indjst.org
Mona Nasar et al. Indian J.Sci.Technol. 


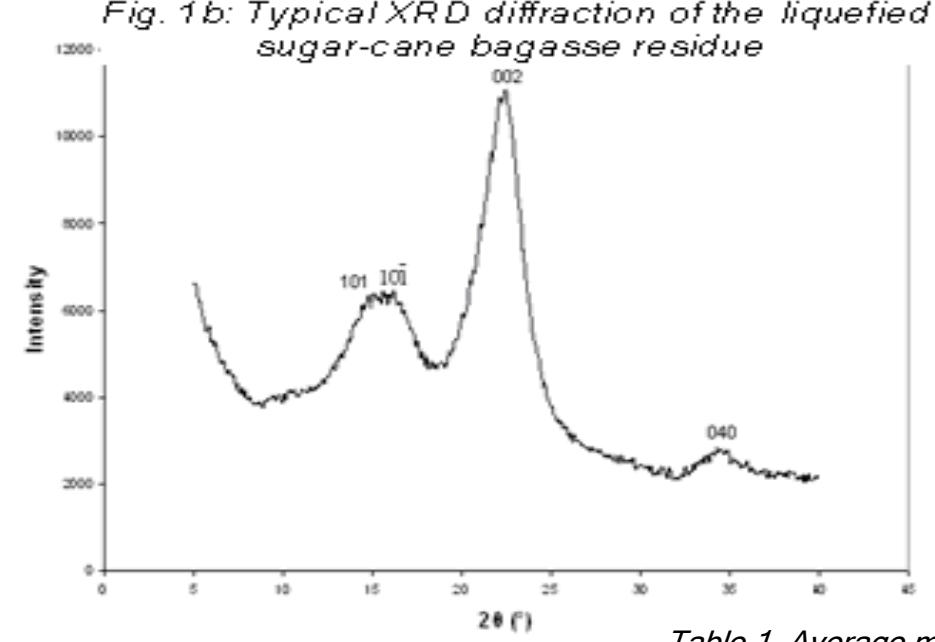

Table 1. Average molecular weight, the number average, and polydispersities

chemicals were of analytical grade. Liquefaction process

Three grams of oven dried sugarcane bagasse; $0.5 \mathrm{~g}$ sulphuric acid and 2 grams phthalic anhydride were mixed according to the predesired composition (5-20 ml ethylene glycol). The mixture was transferred into $1 \mathrm{~L}$ three-necked glass reactor equipped with condenser and a stirring system. The reaction was conducted at temperatures $\left(160-220^{\circ} \mathrm{C}\right)$, at different reaction times $(60-240$ minutes). Liquefied mixture was diluted with acetone and filtered with Whatman medium flow filter paper. The insoluble residue was washed with distilled water and oven dried at $105^{\circ} \mathrm{C}$ overnight then stored in desiccator. The residue content of the liquefied lignocellulosic material was calculated by the following equation:

$$
\mathrm{RC}, \%=\left(\mathrm{W}_{\mathrm{r}} / \mathrm{W}_{\mathrm{o}}\right) \times 100
$$

Where $\mathrm{RC}$ is the residue content; $W_{r}$ is the oven-dried weight of the residue after filtration and $W_{o}$ is the weight of the initial sugar-cane bagasse (Andrej et al., 2005).

FT-IR spectroscopy

The FT-IR analysis was performed by JASCO FT-IR-6100 Fourier transform infrared spectrophotometer using the $\mathrm{KBr}$ pellet disk method for transmittance measurements.

\section{$X$-ray diffraction analysis}

The degree of crystallinity of the residues was determined by X-ray diffraction. The liquefied sugar-cane bagasse residue was pressed into disk and analyzed with Analytical X PERTPRO Super X-ray diffractometer. The crystallinity index $\left(\mathrm{C}_{\mathrm{r}} \mathrm{l}\right)$ of the liquefied sugar-cane bagasse residue was calculated using the Segal method according to the following equation:

$$
\mathrm{C}_{\mathrm{r}} \mathrm{l}, \%=\left[\left(\mathrm{I}_{002}-\mathrm{I}_{\mathrm{am})} / \mathrm{I}_{002}\right] \times 100\right.
$$

Where / 002 is the intensity of the diffraction from the $(002)$ plane at $2 \theta=22.6$, and $\mathrm{I}_{\mathrm{am}}$ is the intensity of the background scatter measured at $2 \Theta=18.5$ (Segal et al., 1959).

\section{Scanning electron microscope}

The sample micrographs were obtained using JEOL JXA- 840 an Electron PROBE micro analyzer microscope. Samples were prepared by deposition of a thin gold film, sputtered using a Balzers SCD 050 deposition system.

Measurements of molecular weight by Gel Permeation Chromatography (GPC)

The GPC measurements were performed on Gel Permeation Chromatography Agillent 1100, Germany. Measurements were conducted at ambient temperature using tetrahydrofuran as the mobile phase at a flow rate of $1.0 \mathrm{ml} / \mathrm{min}$. liquefied wood samples were dissolved in the same solvent as the mobile phase at a concentration of $5 \mathrm{mg} / \mathrm{ml}$ in solution. The amount of each sample injection was $100 \mu \mathrm{l}$.

Determination of hydroxyl number

Preparation of phthalation reagent: Weigh 111 - $116 \mathrm{~g}$ phthalic anhydride into one quart brown bottle. Add $700 \mathrm{ml}$ pyridine which has been distilled over phthalic anhydride, then the bottle was shaked vigorously until the solution was complete dissolved. Add 16-18 $\mathrm{g}$ imidazole and swirl carefully to dissolve. The reagent must stand overnight. A mixture of $1 \mathrm{~g}$ liquefied sample and $25 \mathrm{ml}$ of phthalation reagent were heated for 20 minutes at $110^{\circ} \mathrm{C}$. After that, $50 \mathrm{ml}$ of pyridine and $25 \mathrm{ml}$ of distilled water were added and the mixture titrated with $1 \mathrm{M}$ sodium hydroxide solution to the equivalence point using a $\mathrm{pH}$ meter. In blank titration, exactly $25 \mathrm{ml}$ of phthalation reagent, $50 \mathrm{ml}$ of pyridine and $25 \mathrm{ml}$ of distilled water were added and the mixture was titrated. The hydroxyl number in $\mathrm{mg} \mathrm{KOH} / \mathrm{g}$ sample was calculated by the following equation:

The hydroxyl number (mg $\mathrm{KOH} / \mathrm{g}$ ) $=[(B-A) \times N \times 56.1 / W]+$ acid number

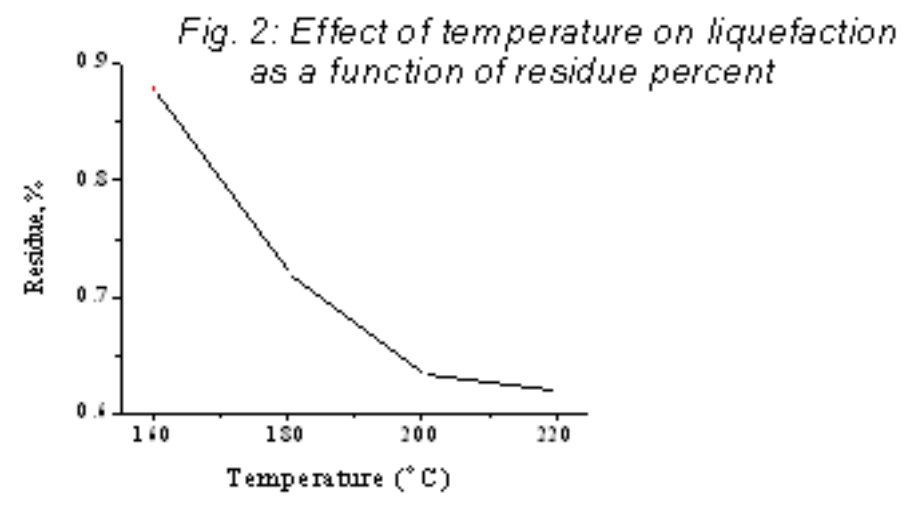

Research article

CCIndian Society for Education and Environment (iSee)
"Sugarcane bagasse liquefaction" http://www.indjst.org
Mona Nasar et al. Indian J.Sci.Technol. 
Where, $\mathrm{A}$ is the volume $(\mathrm{ml})$ of sodium hydroxide solution after the phthalation reaction on liquefied sample; $B$ is the volume of the blank solution $(\mathrm{ml}) ; \mathrm{N}$ is the normality of the sodium hydroxide solution; $\mathrm{W}$ is the weight of the liquefied sample (Mark et al., 2008).

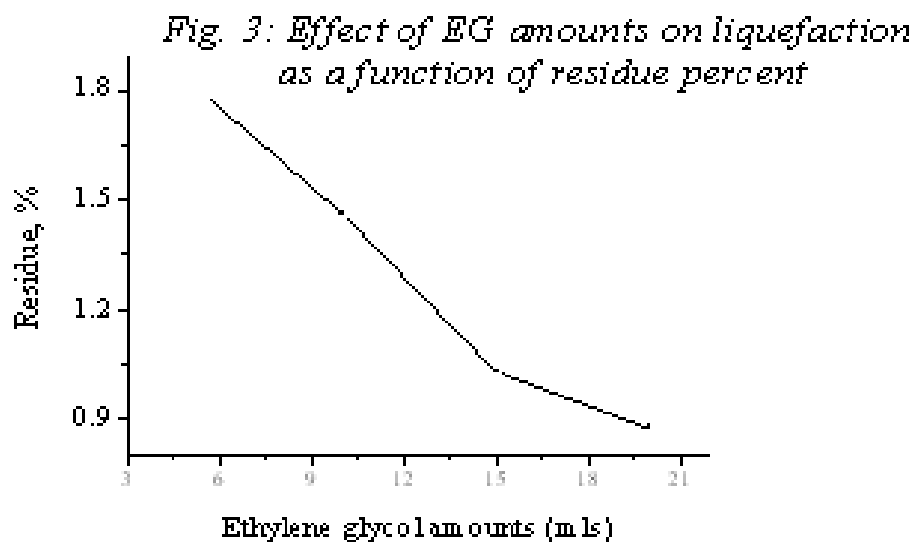

Determination of acid number

A sample of $(8-10 \mathrm{~g})$ depending on the expected acid content was dissolved in $80 \mathrm{ml}$ of dioxane and $20 \mathrm{ml}$ of water at room temperature and the solution was titrated with $0.1 \mathrm{~N}$ sodium hydroxide solution to the equivalence point using a $\mathrm{pH}$ meter. The acid number in $\mathrm{mg} \mathrm{KOH} / \mathrm{g}$ sample was calculated by the following equation:

The acid number $(\mathrm{mg} \mathrm{KOH} / \mathrm{g})=(\mathrm{C}-\mathrm{B}) \times \mathrm{N} \times 56.1 / \mathrm{W}$ Where, $C$ is the titration volume $(\mathrm{ml})$ of the sodium hydroxide solution at the equivalence point; $B$ is the volume of the blank solution $(\mathrm{ml}) ; \mathrm{N}$ is the normality of the sodium hydroxide solution; $W$ is the weight of liquefied sample (Yasuji K et al., 1999).

Results and discussion

Residue characterization

Time, temperature, and ethylene glycol amountsdependence of the sugar- cane bagasse liquefaction, were studied. Fig. 1, 2 and 3 showed the effect of time, temperature, and ethylene glycol amounts on liquefaction as a function of residue percent respectively. The undissolved residue percent decreased steadily beyond 180 minutes, where the residue percent decreases until constant with the reaction progress to be $0.878 \%$ based on the dry weight of the original sample. However, with increasing temperatures, the undissolved residue decreased beyond $200^{\circ} \mathrm{C}$ until constant value. On the other hand, the residue percent showed a positive correlation with increasing ethylene glycol amounts. As expected, the residue percent decreased as ethylene glycol amount increased this may be ascribed to the excess of ethylene glycol which causes proper

Research article

CIndian Society for Education and Environment (iSee) stirring of the reaction, and thus more penetration into lignocellulosic materials components to be chemically derivatived. It is known that lignin is very susceptible to the liquefaction and the decomposed lignin has tendency to undergo a re-condensation reaction (Lin et al., 1996; Eberhardt et al., 2007). However, an excessive amount of ethylene glycol could effectively retard the re-condensation of the decomposed components decreasing the undissolved residue components.

FT-IR spectroscopy of residue

Fig.4 explains simple comparison between the untreated sugar-cane bagasse sample and its liquefied residue. By comparing FT-IR spectra of residue and original sugar-cane bagasse, a broad peak at around 3400 $\mathrm{cm}^{-1}$ represents $\mathrm{OH}$ groups either from cellulose or lignin. The peak at around $2922 \mathrm{~cm}^{-1}$ represents the $\mathrm{C}-\mathrm{H}$ a symmetric stretching in aliphatic methyl. An intense peak appears at around $1734 \mathrm{~cm}^{-1}$ is due to ester carbonyl stretching (its intensity is 95.29). This absorption band mainly arises from the carbonyl stretch in unconjugated

\section{Fig. 4: FT-IR spectra of untreated sugar-cane bagasse and its residue}
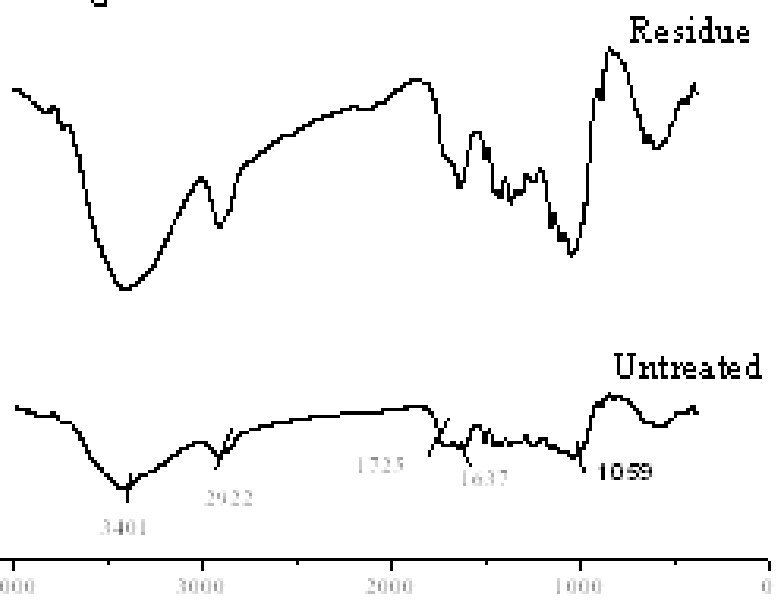

ketone, ester, or carboxylic groups in carbohydrates (hemicelluloses) and not from lignin (Hoareau et al., 2004; Schwanninger et al., 2004). canbagasse (5a), liquefied residue (5b-d)

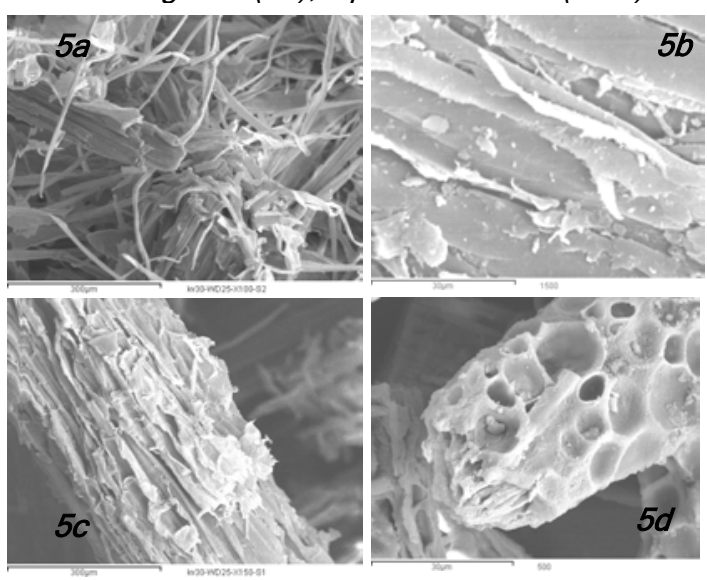

"Sugarcane bagasse liquefaction" http://www.indjst.org band at $1734 \mathrm{~cm}^{-1}$ in the spectra is most likely attributed to ester carbonyl group in xylan. Band at $1734 \mathrm{~cm}^{-1}$ in the spectra of residue showed small shoulder (its intensity is 64.43) is very similar to that of natural cellulosic fiber treated with sodium hydroxide (Mwaikambo et al., 2002; Sun et al., 2004). This phenomenon of alkali treated fibers has been interpreted as the hydrolysis of the ester linkages in the xylan 
(Cyran et al., 2004).

Xylans are closely associated with other plant cell wall constituents, such as lignin and pectic polysaccharides, by ferulic acid or uronic acid thought ester linkages (Sun et al., 1998; Kacurakova et al., 1999). In the presence of alkalis, the hydroxyl ions cause the saponification of these ester linkages and peel off the hemicelluloses from their neighboring lignin or cellulose into solution (Sun et al., 1999; Xu, 2006). A band at approximately $1636 \mathrm{~cm}^{-1}$ is characteristic to $\mathrm{C}=\mathrm{C}$ stretching vibration in aromatic skeletal of lignin. This peak occurred in both residue and original lignocellulosic materials. Peak is at around $899 \mathrm{~cm}^{-1}$ which is due $\beta$-glycosidic linkage. A band appears at approximately at $1458 \mathrm{~cm}^{-1}$ is due to bending vibration of $\mathrm{C}-\mathrm{H}$ of methylene group (scissoring vibration). Residue and untreated sample showed a band at $1059 \mathrm{~cm}^{-1}$ which dominates the spectrum of cellulose linkages.

$X$-ray analysis

The liquefied sugar-cane bagasse displayed a typical X-ray diffraction pattern as that of cellulose I (Fig.1b). In general, the $\mathrm{C}_{\mathrm{r}} \mathrm{l}$ of the liquefied sugar-cane bagasse residue is higher than that of the original bagasse sample. The crystallinity index $\left(\mathrm{C}_{\mathrm{r}} \mathrm{l}\right)$ of the liquefied sugar-cane bagasse residue from the optimum liquefaction conditions was 52.38 compared with blank sample 44.44. These results were expected because of the increasing amount of lignin removed from the amorphous region of the liquefied sugar-cane bagasse residue and consequently, crystallinity increased.

\section{Scanning electron microscope}

The SEM images of the liquefied residue are shown in Fig. $5 a$ \& 5 (b, c, and d). The surface of the fibers is rough and many small fragments of cell wall components are present due to the mechanical processing. As seen most small fragments attached on the surface of the residue fibers have been removed but the liquefied bagasse residue mostly remained in its original fiber bundles.

\section{Characterization of liquid product FT-IR spectra}

Figure 6 showed the FT-IR spectrum of liquefied sample polyol at different liquefaction conditions. A broad peak around $3400 \mathrm{~cm}^{-1}$ represents $\mathrm{OH}$ groups either from cellulose or lignin. An intense peak appears around 1704 $\mathrm{cm}^{-1}$ is due to carbonyl group in phthalate ester. A band at approximately $1636 \mathrm{~cm}^{-1}$ is characteristic to $C=C$ stretching vibration in aromatic skeletal of lignin. The bands of benzene rings at $1607,1514,1459$, and $1118 \mathrm{~cm}^{-1}$ were noticed which indicate the presence of lignin degradation products. Liquid samples showed a band at $1062 \mathrm{~cm}^{-1}$ which dominates the spectrum of cellulose. Peaks around $1431,1371,1164 \mathrm{~cm}^{-1}$ indicate the presence of cellulose degradation products in liquid sugar-cane bagasse.

Measurement of molecular weight by (GPC): The average molecular weight, $M_{w}$, the number average, $M_{n}$, and the polydispersities were gathered in Table 1 . The effect of time, temperature, and ethylene glycol amounts on molecular weight is presented in Table 1, showed an increase in molecular weight with times, and had slightly higher $M_{w}, M_{n}$ at 180 minutes On the other hand, the liquefaction conducted at different temperatures showed slightly no change in average molecular weight and average number molecular weight. However, liquefaction conducted with different amounts of liquefying agent showed reverse trend with decreasing amount of ethylene glycol and $M_{w}, M_{n}$ increased. This can be explained on the possibility that a recondensation reaction of decomposed lignin can be favored under low ethylene glycol amount.

\section{Fig. 6: FT-IR spectrum of liquid sugar-cane bagasse polyol}
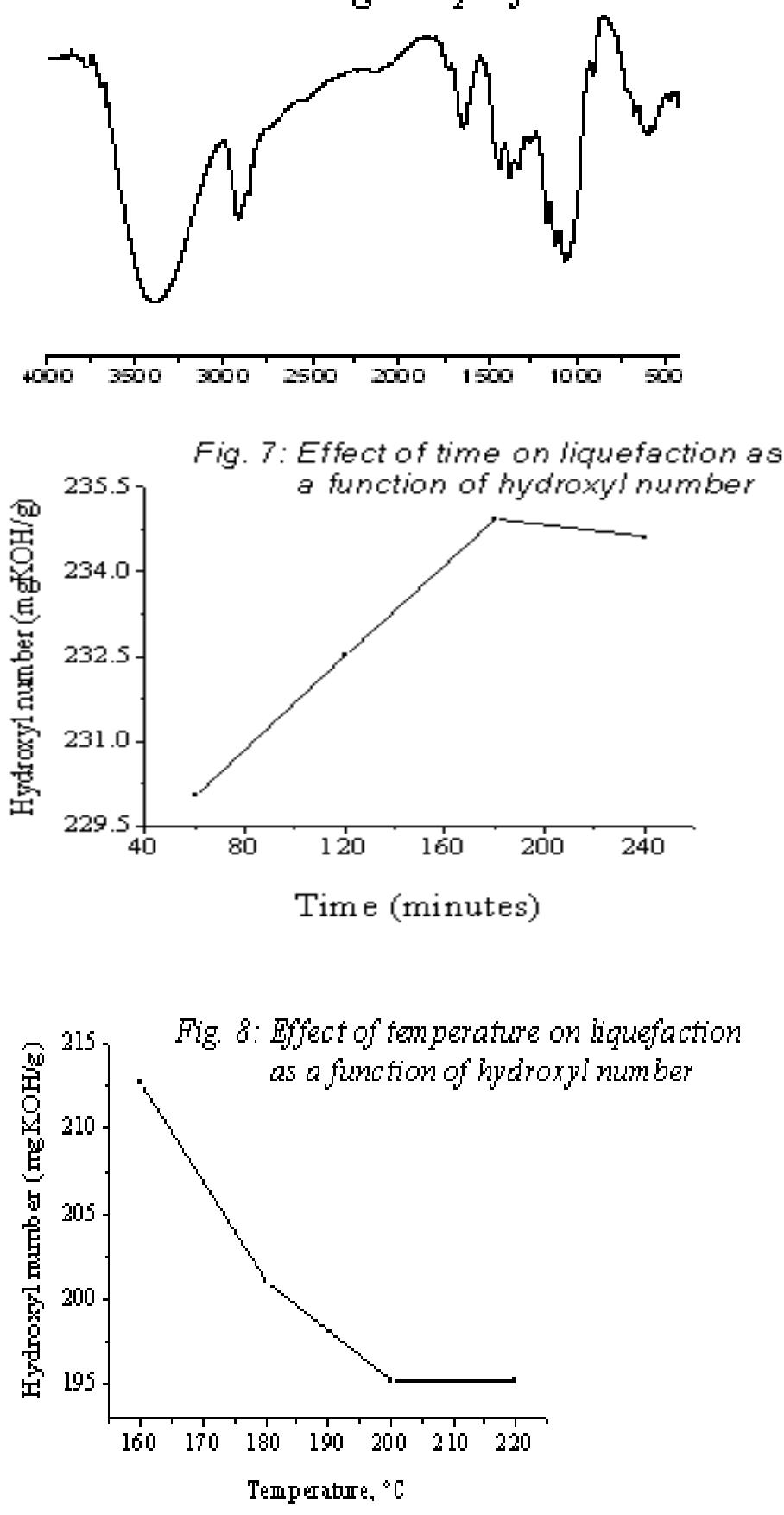

Research article CIndian Society for Education and Environment (iSee)
"Sugarcane bagasse liquefaction" http://www.indjst.org
Mona Nasar et al. Indian J.Sci.Technol. 


\section{Hydroxyl number}

The time, temperature, and ethylene glycol amounts dependence on hydroxyl number results in the liquefaction is shown in Fig.7, 8, and 9 respectively. Hydroxyl number showed a positive correlation with prolonged time beyond 120 minutes, where the hydroxyl number steadily increased until constant value. However, the liquefaction dependence on temperature showed an inverse relationship, the steadily decrease of the Hydroxyl number. These results may be due to either the dehydration or thermal oxidative degradation or due to the reaction between ethylene glycol and dissolved lignocellulosic components. Yao et al. (1999) and Yamada et al. (1995) reported that alcohol-D-glycosides were produced by the alcoholysis between polysaccharides and some alcohols under the same conditions of temperature and catalyst (sulphuric acid) concentration. The same condensation reaction possibly took place in liquefaction process. Carboxylic groups are ordinarily present in the same components of lignocellulosic material and can also be formed by oxidation of carbohydrates and lignin. The esters produced by dehydration between the carboxyl groups and ethylene glycol molecules in the presence of sulfuric acid have the potential to reduce the hydroxyl numbers of liquefied lignocellulosic material. However, rates of oxidation of carbohydrates and lignin are probably lower than that of alcoholysis under $160^{\circ} \mathrm{C}$, since a smooth decrease in hydroxyl numbers was recognized after $160^{\circ} \mathrm{C}$. On the other hand, the effect of ethylene glycol amounts on liquefaction, as a function of hydroxyl number, showed an increase in the hydroxyl number as ethylene glycol amounts increased. Less proper amount of ethylene glycol amounts may cause re-condensation of liquefied lignocellulosic components and hence re-condensation reaction will be accelerated.

Acid number: The results of time, temperature, and ethylene glycol amounts effect on liquefaction as a function of acid number were presented in Fig.10, 11, and 12 respectively. As expected the introduction of mineral acid in the liquefaction as catalyst of etherification and esterification reactions, the acid number $(\mathrm{mg} \mathrm{KOH} / \mathrm{g}$ sample) decreased as liquefaction time increased (Rezzoug et al., 2003). The decrease of the acid value with the increasing in the temperature may be attributed to the production of alcohol-D-glycosides by alcoholysis between polysaccharides and some alcohols under the same conditions of temperature and catalyst (sulphuric acid) concentration. The esters produced by dehydration between the carboxyl groups and ethylene glycol molecules in the presence of sulphuric acid have the potential to reduce the acid numbers of liquefied lignocellulosic material. As expected the acid numbers decreased as ethylene glycol amount increased and this may be ascribed to the excess ethylene glycol which causes prolonged liquefaction extent and consequently, more extent of etherification and esterification reactions in the presence of sulfuric acid as catalyst.

Research article OIndian Society for Education and Environment (iSee)
"Sugarcane bagasse liquefaction" http://www.indjst.org
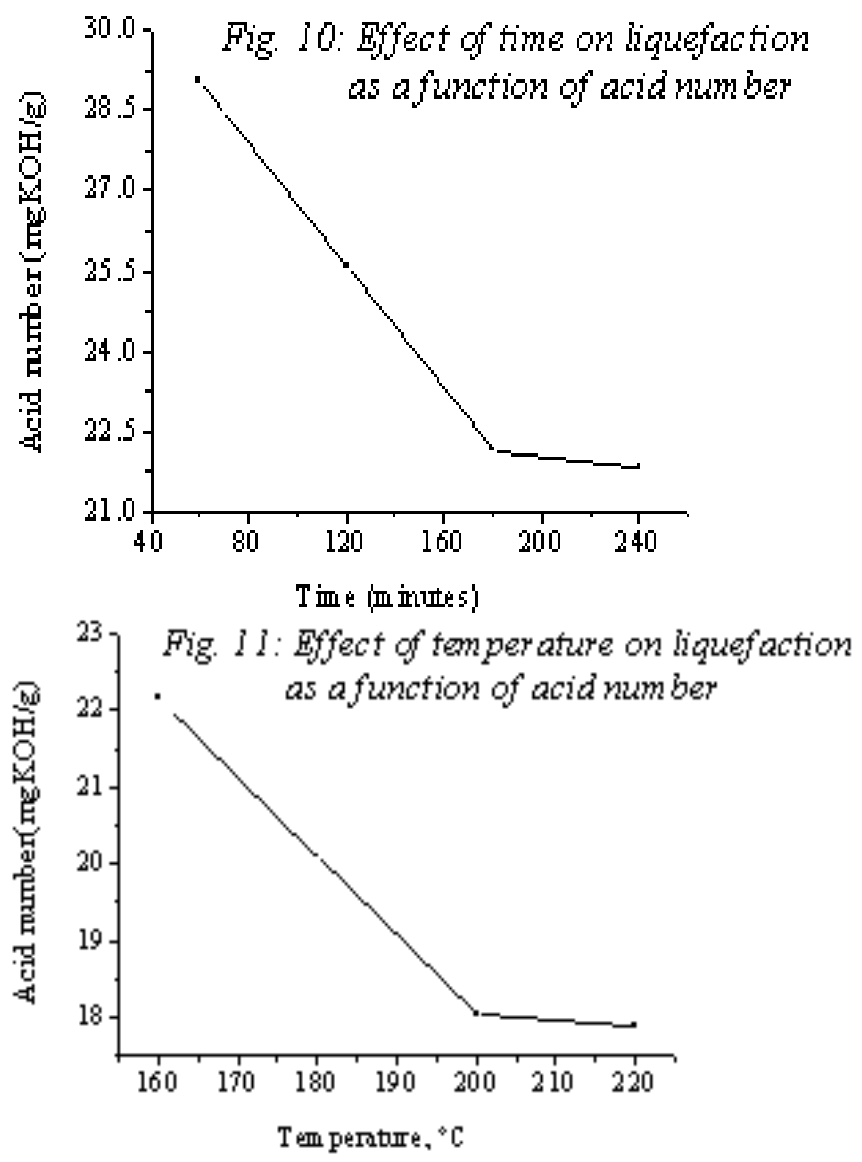

Fig. 12: Effect of EG amounts on liquefaction

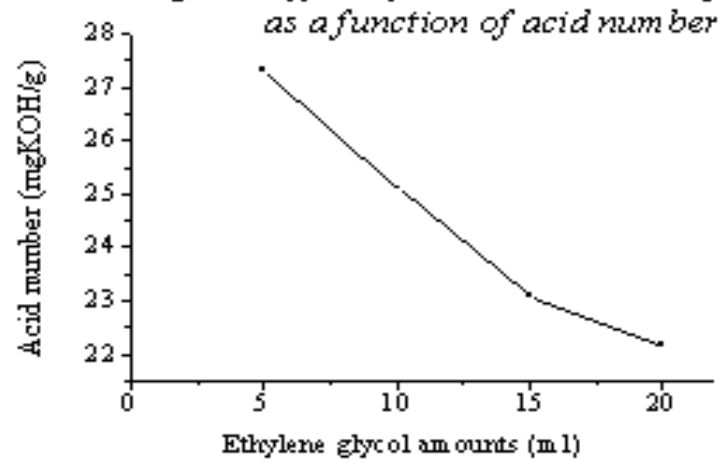

Fig. 9: Effect of EG on liguefaction as a function of hydroxyl num ber

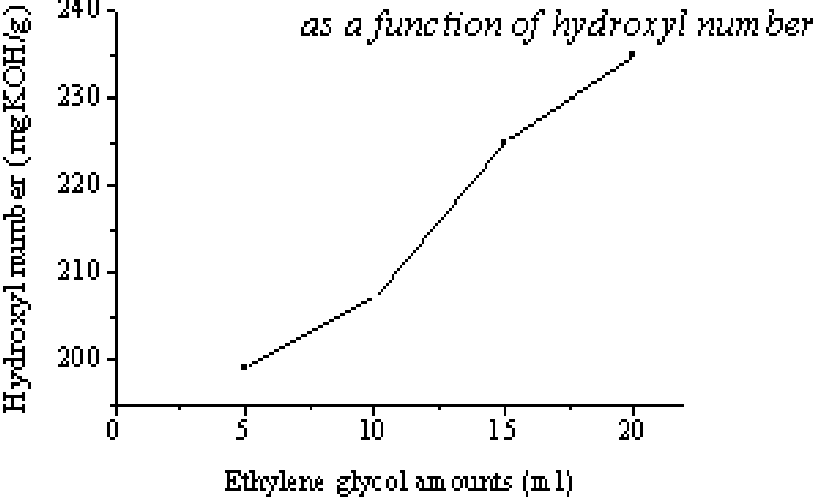

Ettcylere ghyol an ourtes (m l) 


\section{Conclusion}

The liquefaction of sugar-cane bagasse using ethylene glycol system showed a strong influence on time, temperature and ethylene glycol amounts. This liquefying system is recommended for liquefaction of lignocellulosic materials due to its retardation effect on liquefaction component. This system showed higher hydroxyl number at 180 minutes, $160^{\circ} \mathrm{C}$, and $20 \mathrm{ml}$ ethylene glycol for each three grams of sugar-cane bagasse. In our future study, we will synthesize polyurethane rigid foams using liquefied product to investigate their mechanical, thermal, and physical properties.

\section{References}

1. Rezzoug SA and Carpart R (2002) Solvolysis and hydro treatment of wood to provide fuel. Biomass Bioenergy. 72, 631-644.

2. Andrej Krzan, Matjaz Kunaver and Vensz Tisler (2005) Wood liquefaction using dibasic organic acids and glycols. Acta Chim. Slov. 52, 253-258.

3. Cyran M, Courtin CM and Delcour JA (2004) Heterogeneity in the fine structure of alkali-extractable arabinoxylans isolated from two rye flours with high and low bread making quality and their coexistence with other cell wall components. J. Agric. Food. Chem. 52, 2671-2680.

4. Eberhardt TL, Li X, Shupe TF and Hse CY (2007) Chiense Tallow tree utilization: Characterization of extractives cell wall chemistry. Wood Fiber Sci. 39(2), 319-324.

5. Hoareau W, Trindade WG, Siegmund B, Castellan A and Frolini E (2004) Sugar-cane bagasse and curaua lignins oxidatized by chlorine dioxide and reacted with furfuryl alcohol: characterization and stability. Polym. Degrad. Stab. 86, 567576.

6. Kacurakova M, Wellner N, Ebringerova A, Hromadkova Z, Wilson RH and Belton PS (1999) Characterization of xylan-type polysaccharides and associated cell wall components by FT-IR and FT-Raman spectroscopies. Food Hydrocolloids. 13, 35-41.

7. Kobayashi M, Asano T, Kajiyama M and Tomita B (2004) Analysis on residue formation during wood liquefaction with polyhydric alcohols. J. Wood Sci. 50, 407-414.

8. Kobayashi M, Asano T, Kajiyama M and Tomita B (2005) Effect of ozone treatment of wood on its liquefaction. J. Wood Sci. 51, 348-356.

9. Kobayashi M. Enjyouji I. Tomita B and Hatono Y (2000) Liquefied wood /epoxy resin adhesives. In: Wood Adhesives, Forest Products Soc. Madison, USA. 267-272.

10. Krzan A, Matjaz Kunaver and Vensz Tisler (2005) Wood liquefaction using dibasic organic acids and glycols. Acta Chim. Slov. 52, 253-258.

11. Kurimoto $Y$, Doi $S$ and Tamura $Y$ (1999) Species effects on wood liquefaction in polyhydric alcohols. Holzforschung. 53, 617-622.

12. Kurimoto $Y$, Takeda M, Doi S, Tamura $Y$ and Ono $H$ (2001) Network structures and thermal properties of polyurethane films prepared from liquefied wood with polymeric MDI. Bioresour. Technol. 74, 151-157.

13. Lee SH, Ohkita T and Teramoto Y (2005) Polyol recovery from biomass-based polyurethane foam by glycolysis. J. Appl. Polym. Sci. 95, 975-980.

14. Lee SH, Yoshioka M and Shiraishi N (2000) Liquefaction of corn bran in the presence of alcohols and preparation of polyurethane foam from its liquefied polyol. J. Appl. Polym. Sci. 78, 319-325.

Research article

CIndian Society for Education and Environment (iSee)
15. Lin LZ (1996) Characterization of phenolated wood and study on liquefaction mechanism of lignin. PhD dissertation, Kyoto Univ.

16. Mark A. Carey, Stephen L. Wellon Aid and Decker K. Elder (2008) Rapid method for measuring the hydroxyl content of polyurethane. In: Polyurethane Technical Conference, Marriott, Rivercenter in San Antonio, Texas. pp:1-11.

17. Mwaikambo LY and Ansell MP (2002) Chemical modification of hemp, sisal, jute, and kapok fibers by alkalization. J. Appl. Polym. Sci. 84, 2222-2234.

18. Rezzoug, SA and Carpart R (2003) Assessment of wood liquefaction in acidified ethylene glycol using experimental design methodology. Energy Convers. Mgmt. 44, 781-792.

19. Schwanninger M, Rodrigues JC and Hinterstoisser B (2004) Effects of short- time virbratory ball milling on the shape of FTIR spectra of wood and cellulose. Vib. Spectros. 36, 23-40.

20. Segal L, Creely JJ, Martin AE and Conard CM (1959) An empirical method for estimating the degree of crystallinity of native cellulose using X-ray diffractometer. Textile Res J. 29, 786-794.

21. Sun JX, Mao FC, Sun XF and Sun RC (2004) Comparative study of hemicelluloses isolated with alkaline peroxide from lignocellulosic materials. J. Wood Chem. Technol. 24, 239-262.

22. Sun RC, Fang JM, Rowlands $P$ and Bolton J (1998) physicochemical and thermal characterization of wheat straw hemicelluloses and cellulose. J. Agric. Food Chem. 46, $2804-$ 2809.

23. Sun RC and Hughes S (1999) Fractional isolation and physicchemical characterization of alkali-soluble polysaccharides form sugar beet pulp. Carbohydr. Polym. 38, 273-281.

24. Tohmura SI, Li GY and Qin TF (2005) Preparation and characterization of wood polyalcohol based isocyanate adhesive. J. Appl. Polym. Sci. 98, 791-795.

25. Wei Y, Cheng F, Li H and Yu J (2004) Synthesis and properties of polyurethane resins based on liquefied wood. $J$. Appl. Polym. Sci. 92, 351-356.

26. Xu F, Sun JX, Liu CF and Sun RC (2006) Comparative study of alkali and acidic organic solvent-soluble hemicellulosic polysaccharides from sugar-cane bagasse. Carbohydr. Polym. 341, 253-261.

27. Yamada T, Hu Y and Ono $H$ (2001) Condensation reaction of degraded lignocellulose during wood liquefaction in the presence of polyhydric alcohols. J. Adhesive Soc. Japan. 37(2), 471-478.

28. Yamada T, Ohara S, Kato A and Ono H (1995) Behavior of cellulose during liquefaction of wood (3). The $40^{\text {th }}$ Anniversary Conf. of the JWRS. P: 289.

29. Yao Y, Yoshioka M and Shiraishi N (1999) Soluble properties of liquefied biomass prepared in organic solvents. I. The soluble behavior of liquefied biomass in various diluents. Mokuai. Gakkaishi. 40(2), 176-184.

30. Yao Y, Yoshioka M and Shiraishi N (1995) Rigid polyurethane foams from combined liquefaction mixtures of wood and starch. Mokuzai Gakkaishi. 41(7), 659-668.

31. Yasuji Kurimoto, Shuichi Doi and Yasuo Tamura (1999) Species effects on wood liquefaction in polyhydric alcohols. Holzforschung. 53, 617-622.

"Sugarcane bagasse liquefaction" http://www.indjst.org

Mona Nasar et al. Indian J.Sci.Technol. 